\title{
PHASE TRANSFORMATIONS AND MECHANICAL PROPERTIES OF THE NITINOL ALLOY WITH SHAPE MEMORY
}

\author{
V.P. Iasnii ${ }^{1,2}$ and R. Junga ${ }^{3}$
}

UDC 539.3

\begin{abstract}
We study the $\mathrm{Ni}_{55.8} \mathrm{Ti}_{44.2}$ alloy in the form of rods $8 \mathrm{~mm}$ and wires $1.5 \mathrm{~mm}$ in diameter. By the method of differential scanning calorimetry, we find the temperatures of phase transformations different for the rods and the wires. The stresses corresponding to the onset and termination of phase transformations at room temperature are determined. We also analyze the influence of the diameters of specimens on the temperatures of phase transformations, deformation of behavior of the alloy, and its mechanical characteristics.
\end{abstract}

Keywords: $\mathrm{Ni}-\mathrm{Ti}$ alloy, temperatures of phase transformations, stress-strain diagram, scaling factor.

Shape-memory alloys (SMAs) [1,2] belong to the class of functional materials exhibiting the effects of shape memory and pseudoelasticity $[1,3,4]$. Their application depends on the temperatures of phase transformations and mechanical properties because they frequently suffer the action of mechanical loads.

As an especially important characteristic of SMAs, we can mention the temperature of phase transitions because, at lower temperatures, the material is in the martensitic phase, whereas at higher temperatures, it is in the austenitic phase. The temperature of phase transitions is, as a rule, determined by the method of thermal analysis, i.e., by using the procedure of differential scanning calorimetry (DSC) [5,6]. This procedure requires only several milligrams of the material [7]. Due to its simplicity and the high rate of investigations, this method is used most extensively. It is realized by measuring the difference between the amounts of heat required to increase the temperature of tested and reference specimens as a function of temperature.

The aim of the present work is to study the temperatures of phase transformations of Nitinol, Ni-Ti alloy, and to determine its basic mechanical characteristics at temperatures closed to the room temperature.

\section{Specific Features of Experimental Procedures}

We study a $\mathrm{Ni}-\mathrm{Ti}$ alloy with the following composition: $\mathrm{Ni}_{55.8} \mathrm{Ti}_{44.2}$ (nitinol) either in the form of rods $8 \mathrm{~mm}$ in diameter or in the form of wires $1.5 \mathrm{~mm}$ in diameter by the Wuxi Xin Xin Glai Steel Trade Co., LTD (China) [8]. The chemical composition of the alloy claimed in the certificate is as follows: $55.78 \% \mathrm{Ni}$; $0.005 \% \mathrm{Co} ; 0.005 \% \mathrm{Cu} ; 0.005 \% \mathrm{Cr} ; 0.012 \% \mathrm{Fe} ; 0.005 \% \mathrm{Nb} ; 0.032 \% \mathrm{C} ; 0.001 \% \mathrm{H} ; 0.04 \% \mathrm{O} ; 0.001 \% \mathrm{~N}$; and $44.12 \% \mathrm{Ti}$. The mechanical properties of the alloy at room temperature are as follows: its ultimate strength is equal to $855 \mathrm{MPa}$, yield limit to $228 \mathrm{MPa}$, and relative elongation to $19 \%$.

\footnotetext{
${ }^{1}$ Pulyui Ternopil National Technical University, Ternopil, Ukraine.

${ }^{2}$ Corresponding author; e-mail: v.iasnii@gmail.com.

${ }^{3}$ Politechnika Opolska, Opole, Poland.
}

Translated from Fizyko-Khimichna Mekhanika Materialiv, Vol. 54, No. 3, pp. 107-111, May-June, 2018. Original article submitted March 27, 2018. 


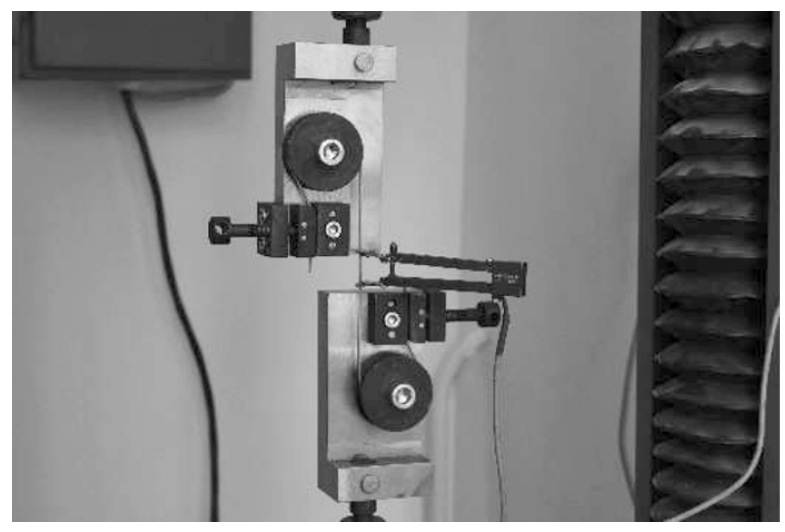

Fig. 1. Grips with a wire and an extensometer aimed at measuring longitudinal deformations installed in a FP-100 machine.

The characteristics of thermal transitions in the course of phase transformations of SMAs were studied by DSC method in a NETZSCH DSC 214 Polyma installation. The cylindrical specimens $\sim 85 \mathrm{mg}$ in weight and $4 \mathrm{~mm}$ in diameter cut out from rods $8 \mathrm{~mm}$ in diameter and the specimens $35 \mathrm{mg}$ in weight cut out from wires $1.5 \mathrm{~mm}$ in diameter were placed on the plate of a crucible made of $\mathrm{Al}_{2} \mathrm{O}_{3}$. The velocity of gas flow was $30 \mathrm{mliter} / \mathrm{min}$. The specimens were heated and cooled from -50 to $115^{\circ} \mathrm{C}$ in the $\mathrm{N}_{2}$ atmosphere at a rate of $10^{\circ} \mathrm{C} / \mathrm{min}$. To improve the reliability of results, each cycle of heating and cooling was repeated three times.

The mechanical properties of SMAs were determined in air at a temperature of $20^{\circ} \mathrm{C}$ for the rods and of $18^{\circ} \mathrm{C}$ for the wires. From the rods, we produced cylindrical specimens $12.5 \mathrm{~mm}$ in length with the diameter of the working section equal to $5 \mathrm{~mm}$ and stretched these specimens in an STM-10 machine. The wires $1.5 \mathrm{~mm}$ in diameter were tested in a modernized FP-100 machine with automatic control and data-collection system [8]. Special grips were used to hold the wire (Fig. 1). The wires were loaded by the displacements of a traverse moving with a velocity of $3 \mathrm{~mm} / \mathrm{min}$, while the specimens $5 \mathrm{~mm}$ in diameter were loaded by a plunger moving with a velocity of $0.25 \mathrm{~mm} / \mathrm{min}$ according to the requirements of [9]. In both cases, we recorded the forces and the longitudinal strains on a measurement base of $12 \mathrm{~mm}$.

\section{Results of Investigations}

The results of the DSC analysis are presented on the "heat flux-temperature (F-T) "coordinates: the curves reveal the martensite-austenite (Figs. 2a, c) and austenite-martensite (Figs. 2b, d) phase transformations running in the SMA in the cycles of heating and cooling, respectively. The comparison of the temperatures of phase transitions confirms the invertible character of changes in the crystallographic structure of the investigated material. In the course of heating, the phase transition occurs within the temperature range between $-30.8^{\circ} \mathrm{C}$ and $28.5^{\circ} \mathrm{C}$ (extrapolation of the mean value) and the temperature of transition is equal to $-1.2^{\circ} \mathrm{C}$. In the process of cooling, the invertible phase transition occurs between $-44.6^{\circ} \mathrm{C}$ and $21.4^{\circ} \mathrm{C}$ and the heat flux is maximum at a temperature of $-9.2^{\circ} \mathrm{C}$.

Similar temperature dependences of the DSC analysis were obtained for the wires (Figs. 2c, d). The comparison of the temperatures of phase transitions obtained in the processes of heating and cooling also corroborates the invertible character of changes in the crystallographic structure of the studied material. In the course of heating, the phase transition occurs within the temperature range between $-30.5^{\circ} \mathrm{C}$ and $28^{\circ} \mathrm{C}$, and the transition temperature is equal to $0.7^{\circ} \mathrm{C}$. At the same time, the austenite-martensite phase transition in the course of cooling occurs between $-44.5^{\circ} \mathrm{C}$ and $22.5^{\circ} \mathrm{C}$ and the heat flux is maximum at $-9.2^{\circ} \mathrm{C}$. 

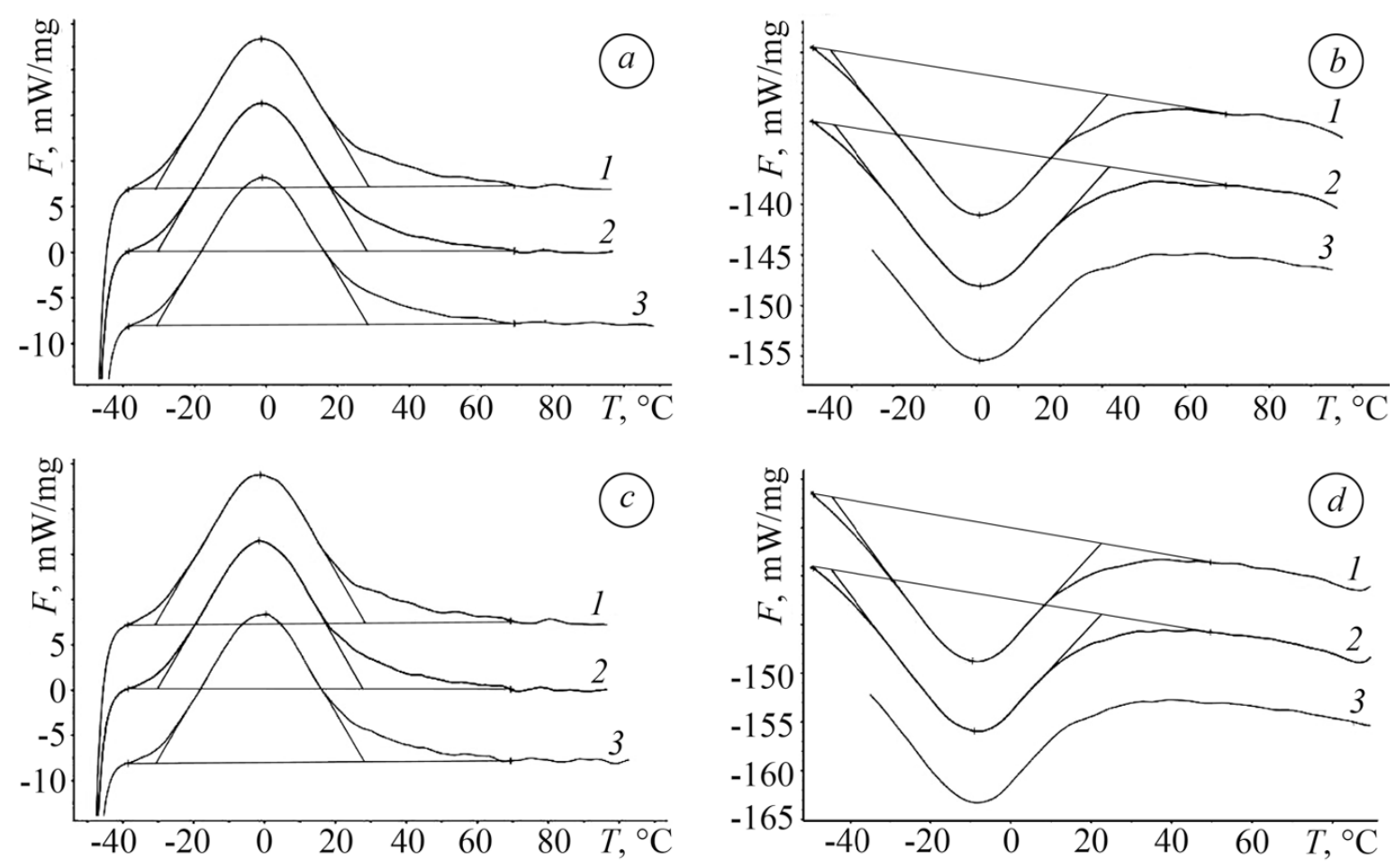

Fig. 2. DSC analysis of the rods (a, b) and wires (c, d) of the SMA for the first (1), second (2), and third (3) cycles of heating (a, c) and cooling (b, d).
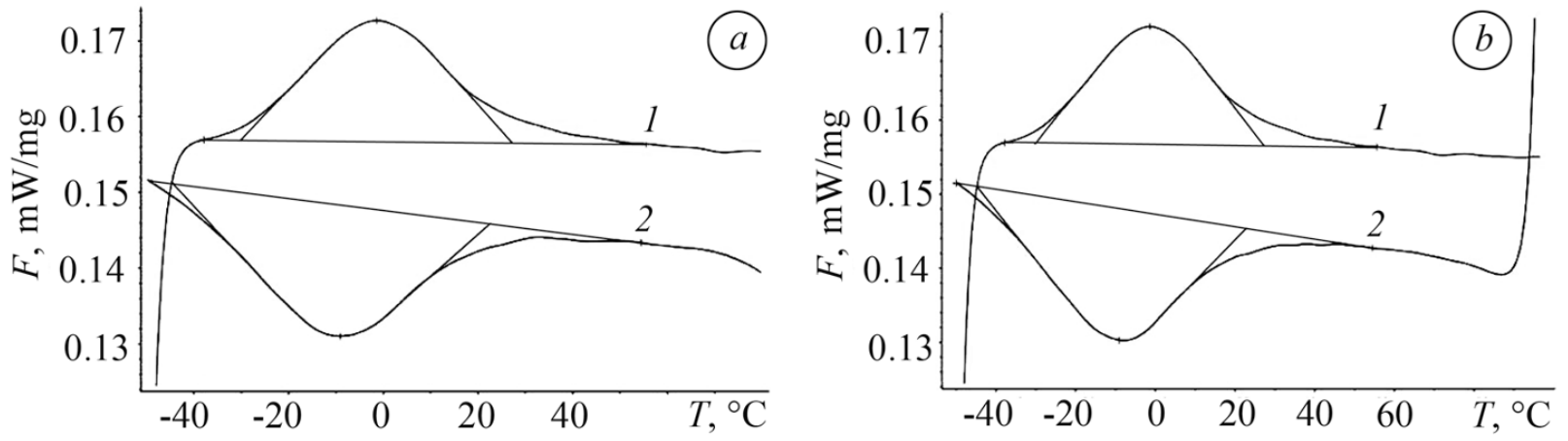

Fig. 3. Variations of enthalpy in the SMA during phase transitions in rods (a) and wires (b) in the course of heating (1) and cooling (2).

The variations of enthalpy caused by the phase transitions in the rods are $3.547 \mathrm{~J} / \mathrm{g}$ in the course of heating and $3.475 \mathrm{~J} / \mathrm{g}$ in the course of cooling; for the wires, the corresponding quantities are equal to $3.547 \mathrm{~J} / \mathrm{g}$ and $3.78 \mathrm{~J} / \mathrm{g}$, respectively (Figs. 3a, b).

In Table 1, we present the generalized data on the temperatures of phase transformations of the studied SMA. Here, $M_{s}, M_{f}, A_{s}$, and $A_{f}$ are the temperatures of the onset and termination of transformations of the martensitic and austenitic phases, respectively. Note that the temperatures of phase transformations in the wire material reveal an insignificant dispersion between separate cycles of heating (cooling) relative to analogous characteristics for the rod. Thus, the maximum deviations from the mean temperature of termination of the austenitic transformation $A_{f}$ are $-0.4^{\circ} \mathrm{C}$ and $7.2^{\circ} \mathrm{C}$ for the rods and wires, respectively. 


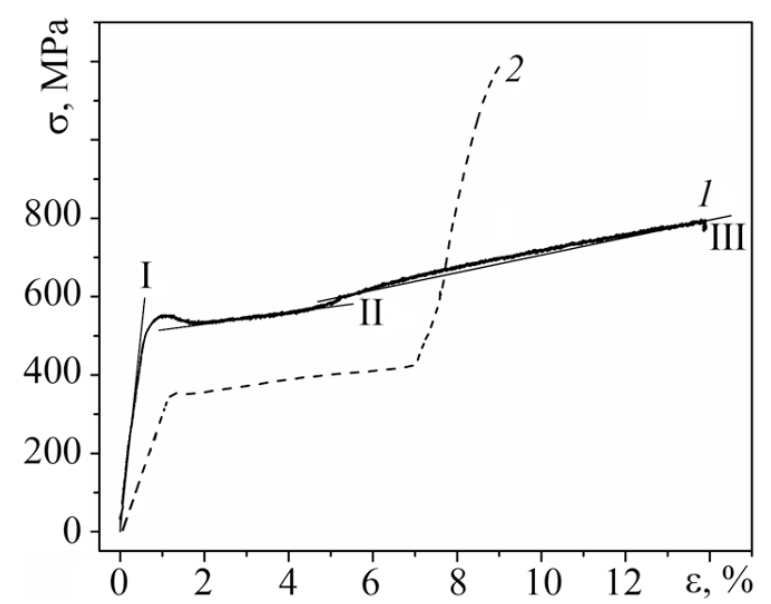

Fig. 4. Stress-strain diagrams for cylindrical specimens $5 \mathrm{~mm}$ in diameter (1) and wires (2); (I, II, and III) correspond to the austenitic, austenitic-martensitic, and martensitic phases, respectively.

Table 1

Temperatures of Phase Transformations in Nitinol

\begin{tabular}{|c|c|c|c|c|c|}
\hline \multirow{2}{*}{ SMA } & \multirow{2}{*}{ Heating / cooling } & $M_{s}$ & $M_{f}$ & $A_{s}$ & $A_{f}$ \\
\hline & & \multicolumn{4}{|c|}{${ }^{\circ} \mathrm{C}$} \\
\hline \multirow{4}{*}{ Wire } & $1 \mathrm{st}$ & 22.5 & -44.5 & -30.9 & 28.3 \\
\hline & 2nd & 22.5 & -44.6 & -30.2 & 27.7 \\
\hline & $3 \mathrm{rd}$ & - & - & -30.6 & 28.2 \\
\hline & Mean value & 22.5 & -44.6 & -30.6 & 28.1 \\
\hline \multirow{4}{*}{ Rod } & $1 \mathrm{st}$ & -0.9 & -32.3 & - & 22 \\
\hline & 2nd & -13.7 & -35.5 & - & 31.9 \\
\hline & $3 \mathrm{rd}$ & 8.0 & -29.9 & - & 20.2 \\
\hline & Mean value & -6.9 & -32.6 & - & 24.7 \\
\hline
\end{tabular}

The mechanical tests were carried out at temperatures close to the temperature of termination of the martensite-austenite transformation $A_{f}$, which is equal to $28^{\circ} \mathrm{C}$ and $24.7^{\circ} \mathrm{C}$ for the wires and rods, respectively (Table 1). The tensile stress-strain diagrams presented in Fig. 4 consist of three sections: Section I with elastic behavior (austenite phase), Section II with pseudoelastic behavior (austenite-martensite phase), where the properties of superelasticity are manifested, and Section III with elastoplastic deformation (martensitic phase), which is terminated by the final fracture of the specimen.

The characteristics of strength are strongly different for specimens with different geometries. Thus, the yield limit (Table 2) and the plateau in the stress-strain diagrams (Fig. 4) are much larger for specimens $5 \mathrm{~mm}$ in diameter. This agrees with the known results (see, e.g., [10]), which show that the stress corresponding to the plateau in the stress-strain diagram increase with testing temperature according to the Clausius-Clapeyron 
Table 2

Mechanical Properties of Nitinol

\begin{tabular}{|c|c|c|c|c|c|c|}
\hline \multirow{2}{*}{ Results } & \multirow{2}{*}{$\begin{array}{c}d, \\
\mathrm{~mm}\end{array}$} & \multirow{2}{*}{$\begin{array}{c}\text { Testing } \\
\text { temperature, }{ }^{\circ} \mathrm{C}\end{array}$} & $\sigma_{0.2}$ & $\sigma_{\mathrm{u}}$ & Elasticity & lulus, GPa \\
\hline & & & \multicolumn{2}{|c|}{$\mathrm{MPa}$} & Section I & Section II \\
\hline $\begin{array}{l}\text { According to } \\
\text { the certificate }\end{array}$ & $8 ; 1.5$ & - & 228 & 855 & - & - \\
\hline Experiment & 8 & 21 & 523 & 780 & 102 & 1.39 \\
\hline Experiment & 1.5 & 18 & 338 & 1196 & 52.7 & 1.36 \\
\hline
\end{tabular}

relation and can be as high as $3-20 \mathrm{MPa} /{ }^{\circ} \mathrm{C}$. However, the ultimate strength is also higher for the wire and is equal to $1196 \mathrm{MPa}$. Note that the determined characteristics of strength strongly differ from the characteristics specified in the delivery certificate. To explain the differences between the values of the characteristics of SMA obtained for specimens 5 and $1.5 \mathrm{~mm}$ in diameter and the values presented in the certificate, it is necessary to perform additional investigations of their chemical compositions.

The higher elasticity modulus of the rod as compared with the wire in the first section of deformation is explained by a higher relative fraction of the austenitic phase in the rod at the testing temperature (Table 2), which is almost equal to the temperature $A_{f}$ (Table 1). In the second section of the stress-strain diagram that describes the course of the austenite-martensite transformation, the elasticity moduli of the rod and the wire coincide with an accuracy to within $2 \%$.

It is also known that, parallel with the chemical composition, the deformation behavior of SMA is also affected by the thickness (diameter) and fluctuations of the temperature of the specimens caused by the heat release (absorption) as a result of the phase transformations in the process of deformation [11].

\section{CONCLUSIONS}

We determined the temperatures of phase transitions (the onset and termination of the austenitic and martensitic transformations) in nitinol in the form of rods $8 \mathrm{~mm}$ in diameter and wires $1.5 \mathrm{~mm}$ in diameter at room temperature. It is shown that the temperature of termination of the austenitic transformation in the material of the rods is much lower than for the wires. We studied the behavior of SMA and determined its mechanical properties under the conditions of tension at room temperature that are somewhat worse than at the temperature of termination of the austenitic transformation. The austenite-martensite transformations in the wires and in the specimens cut out from the rods originate at $330 \mathrm{MPa}$ and $550 \mathrm{MPa}$, respectively. These values are higher than the values specified in the delivery certificate. The yield limit is higher for the material of the rod. At the same time, the material of the wire has a higher ultimate strength.

\section{REFERENCES}

1. S. Miyazaki, S. Kimura, F. Takei, T. Miura, K. Otsuka, and Y. Suzuki, "Shape memory effect and pseudoelasticity in a TiNi single crystal," Scr. Metall., 17, No. 9, 1057-1062 (1983).

2. O. S. Onyshko, "Modeling of the physicomechanical behavior of bodies made of alloys with shape memory in the presence of electric fields," Fiz.-Khim. Mekh.Mater., 53, No. 4, 107-111 (2017); English translation: Mater. Sci., 53, No. 4, 541-547 (2018). 
3. H. Ma and C. Cho, "Feasibility study on a superelastic SMA damper with recentering capability," Mater. Sci. Eng. A, 473, Nos. 1-2, 290-296 (2008).

4. P. Yasniy, M. Kolisnyk, O. Kononchuk, and V. Iasnii, "Calculation of constructive parameters of SMA damper," Sci. J. TNTU, 88, No. 4, 7-15 (2017).

5. J. A. Shaw and S. Kyriakides, "Thermomechanical aspects of NiTi," J. Mech. Phys. Solids, 43, No. 8, 1243-1281 (1995).

6. L. V. Bazyuk and N. V. Meshcheryakova, "Methods for the determination of the enthalpy of metals and alloys (a survey)," Visn. Prykarpat. Nats. Univ. Stefanyka, Ser. Khim., No. 11, 81-89 (2011).

7. K. V. Kodre, S. R. Attarde, P. R. Yendhe, R. Y. Patil, and V. U. Barge, "Differential scanning calorimetry: A review," Res. Rev.J. Pharm. Anal., 3, No. 3, 11-22 (2014).

8. V. Iasnii, V. Brevus, and P. Marushchak, "A method and some results of studies of slow deformation and fracture of heat-resistant steel," Visn. TNTU, 69, No. 1, 7-13 (2013).

9. ASTM F2516-14. Standard Test Method for Tension Testing of Nickel-Titanium Superelastic Materials, ASTM International, Conshohocken (2014)

10. Introduction to Nitinol, Memry Corporation, Bethel-Menlo Park-New Hartford (2017).

11. V. Torra, S. Casciati, and M. Vece, "Shape memory alloys wires: from small to medium diameter," Adv. Sci. Technol. Trans. Tech. Publ., 101, 79-88 (2016). 